\title{
molecules
}

ISSN 1420-3049

http://www.mdpi.org

Full Paper

\section{Solvent Effects in Electrocoagulation of Selected Plant Pigments and Tannin}

Neeranuch Chairungsi ${ }^{1}$, Kanlaya Jumpatong ${ }^{1}$, Weerachai Phutdhawong ${ }^{2, *}$ and Duang Buddhasukh 1,*

${ }^{1}$ Department of Chemistry, Faculty of Science, Chiangmai University, Chiang Mai, 50200, Thailand

2 Department of Chemistry, Faculty of Science, Maejo University, Chiang Mai, 50292, Thailand

* Authors to whom correspondence should be addressed; emails: weerachai@mju.ac.th; duang@chiangmai.ac.th

Received: 9 April 2006; in revised form: 27 April 2006 / Accepted: 29 April 2006 /

Published: 29 April 2006

\begin{abstract}
Electrocoagulation of a plant extract and certain substances representative of selected classes of plant pigments, viz. chlorophyll, a carotenoid, a phenolic substance and a tannin, was performed in ethanol containing varying amounts of water (15-75\%). The results showed that the extent and efficiency of coagulation of these substances tends to vary in a manner directly related to the water content of the solvent, although the tannin and the phenolic substance were less sensitive to the solvent composition and are equally well coagulated in all solvent systems studied. The findings can be applied to the removal of these substances from aqueous alcoholic plant extracts using the electrocoagulation technique.
\end{abstract}

Keywords: Electrocoagulation, electrolytic decolourisation, plant pigments, phenolic compounds, tannins

\section{Introduction}

Electrocoagulation has been a useful alternative technique for clarifying and decolourising certain solutions containing unwanted dissolved substances or suspended matter. However, those solutions were almost always aqueous in nature, for example, potable water [1-2], food wastewater [3], tar-sand and oil-shale wastewater [4], phosphate-containing sewage [5-6], industrial wastes containing cyanide and heavy metals [7-9], and dye-containing textile wastewater [10-11]. Electrocoagulation has also 
been used as a purification step in the isolation of a few natural products from crude plant extracts [1217]. Again, the solvent used in those isolations was also purely aqueous. Trials of natural product isolation using electrocoagulation in alcoholic solutions as a part of the process have been reported in the literature, for example, for the isolation of asiaticoside [18] and the extraction of phenolic compounds from the bark of Lithocarpus elegans [19], but a systematic study of electrocoagulation in alcoholic solutions has, to our knowledge, not been undertaken. In view of the fact that a system containing an organic solvent is undoubtedly more useful in isolating natural products in general, we would like to report our study on the effects of solvent in the electrocoagulation of some selected organic substances and plant extracts. For a start, we chose as our model study the system in which ethanol with varying amounts of water is used as solvent.

\section{Results and Discussion}

Our previous work carried out with water and alcohol soluble natural dyes (chlorophyllin and crocin) [20] showed that although decreases in the water content of the solvent (ethanol) has some effect on the coagulation efficiency for the dyes, coagulation was more or less complete after 2 hours, especially when iron is used for the electrodes (Figures 1-2).

Figure 1. Plots of residual weight percentage and electrolysis time for each ethanol concentration of chlorophyllin solution at $626 \mathrm{~nm}$; A: with aluminium as electrodes, B: with iron as electrodes.

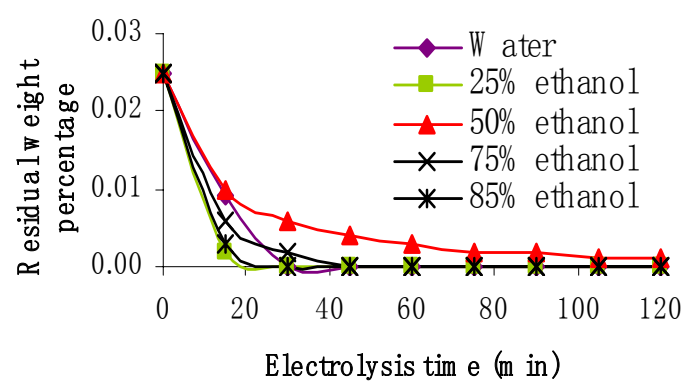

A

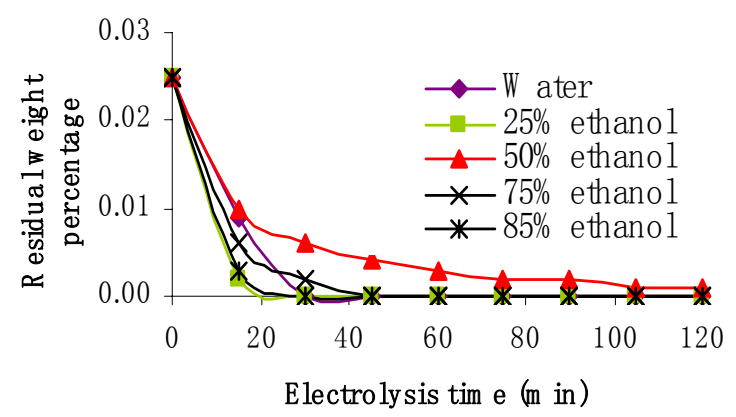

$\mathrm{B}$

Figure 2. Plots of residual weight percentage and electrolysis time for each ethanol concentration of crocin solution at $440 \mathrm{~nm}$; A: with aluminium as electrodes, B: with iron as electrodes.

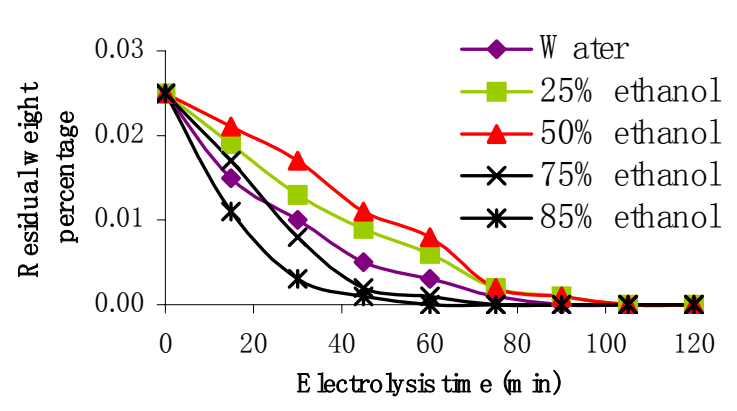

A

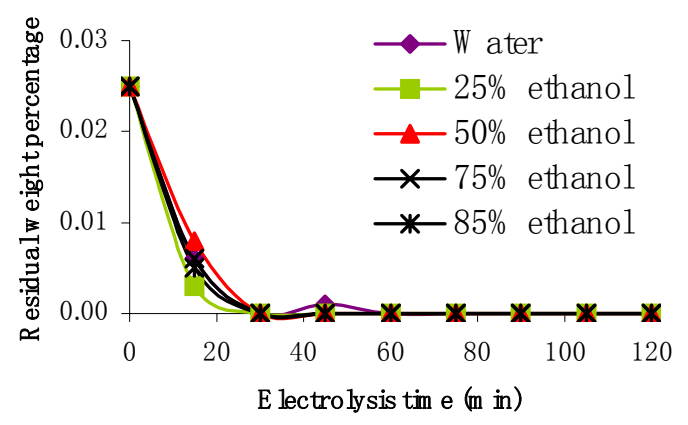

B 
However, experiments carried out in this study with water-insoluble dyes (the chlorophylls and the carotenoids) seem to indicate that, contrary to the above result, these pigments seem to be more difficult to coagulate. For example, in Figure 3 it can be seen that the model pigment $\beta$-carotene is hardly affected and barely removed from the solution by the electrolytic decolourisation process applied, even when iron electrodes are used (due to the difficulties in solubilizing this pigment, electrocoagulation was only examined in a single mixed solvent system.)

Figure 3. Plots of absorbance at $460 \mathrm{~nm}$ and electrolysis time for $\beta$-carotene $(0.01 \%)$ in $27 \%$ ethanol; $\Vdash$ : with aluminium as electrodes, $₫$ : with iron as electrodes.

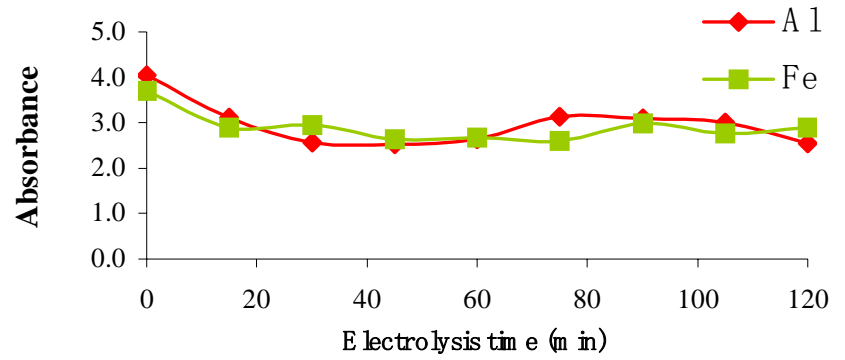

Similarly, for solutions of extracted chlorophyll, the trend is that coagulation seems to be less efficient as the water content in the solvent decreases (Figures 4-5). This may not only be due to the fact that, as the water content in the solvent decreases the process of electrocoagulation itself is naturally retarded, but also to the fact that more pigment is dissolved in the solution as the water content in the solvent decreases and the alcohol content accordingly increases. This trend was repeated in nearly every case of green plant extracts we studied. Thus, for example, when the alcoholic extract of the leaves of Solanum laciniatum, which contain solasonine (an important starting compound for steroid synthesis), was subject to decolourisation by electrocoagulation, typical results as shown in Figure 6 (for the yellow pigments) and Figure 7 (for the green pigments) were obtained.

Figure 4. Plots of absorbance at $440 \mathrm{~nm}$ and electrolysis time for each ethanol concentration of extracted chlorophyll solution; A: with aluminium as electrodes, B: with iron as electrodes; •, 75\% ethanol; $₫$, 85\% ethanol

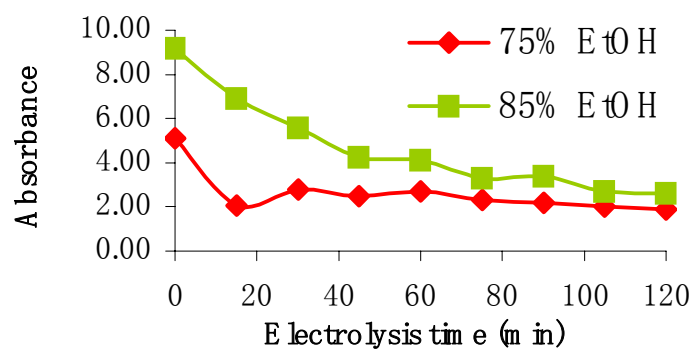

A

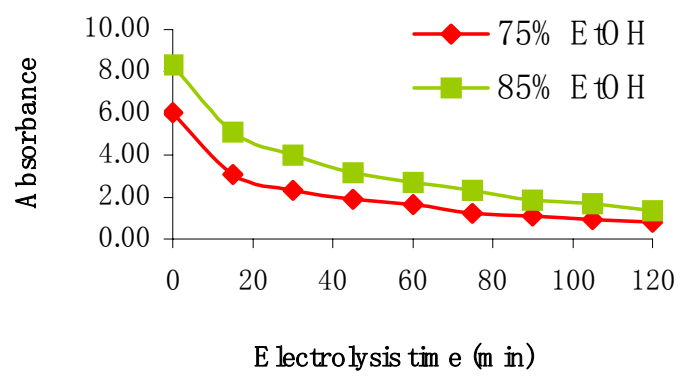

B 
Figure 5. Plots of absorbance at $665 \mathrm{~nm}$ and electrolysis time for each ethanol concentration of extracted chlorophyll solution; A: with aluminium as electrodes, B: with iron as electrodes; • 75\% ethanol; $₫$, 80\% ethanol

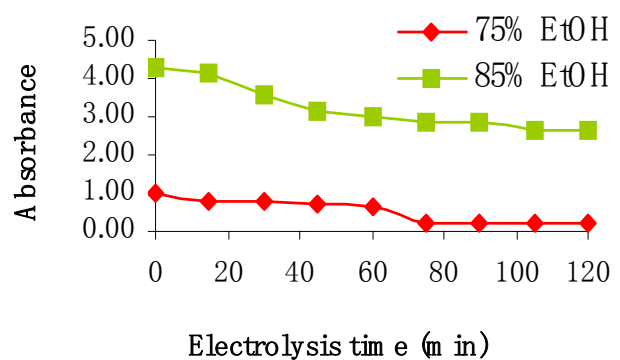

A

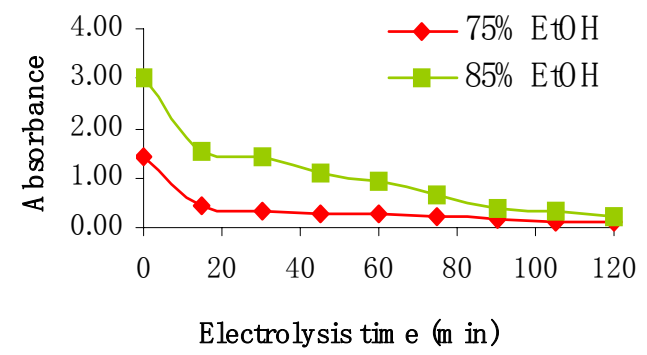

B

Importantly, however, it has been shown by our group that even with this general decreased efficacy of the pigment removal, electrocoagulation is still more efficient than the conventional method of extraction with organic solvents and does not affect the desired natural products, which were subsequently isolated [21].

Figure 6. Plots of absorbance and electrolysis time for each ethanol concentration of Solanum laciniatum extract at $408 \mathrm{~nm}$; A: with aluminium as electrodes, B: with iron as electrodes; $\downarrow$, 25\% ethanol; $\square, 50 \%$ ethanol; $\boldsymbol{\Delta}$, 75\% ethanol; $\times$, $85 \%$ ethanol.

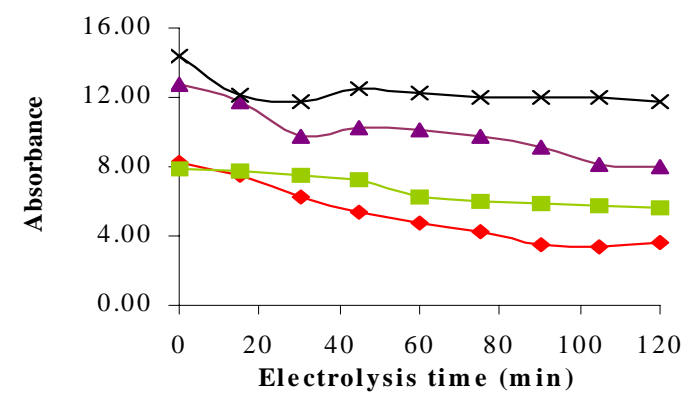

A

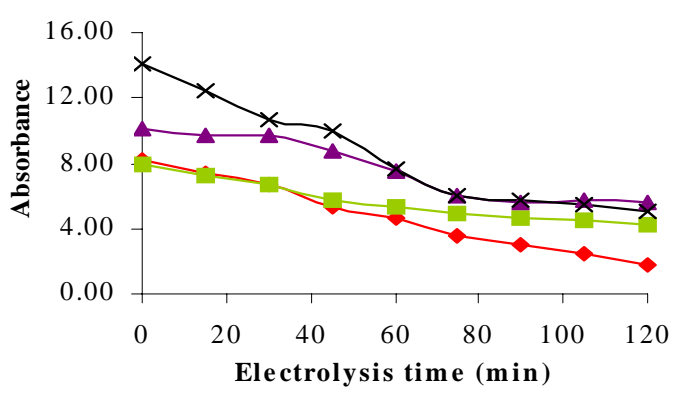

B

Figure 7. Plots of absorbance and electrolysis time for each ethanol concentration of Solanum laciniatum extract at $666 \mathrm{~nm}$; A: with aluminium as electrodes, B: with iron as electrodes; $\bullet$, 25\% ethanol; $\sqsubset, 50 \%$ ethanol; $\boldsymbol{\Delta}$, $75 \%$ ethanol; $\times$, $85 \%$ ethanol

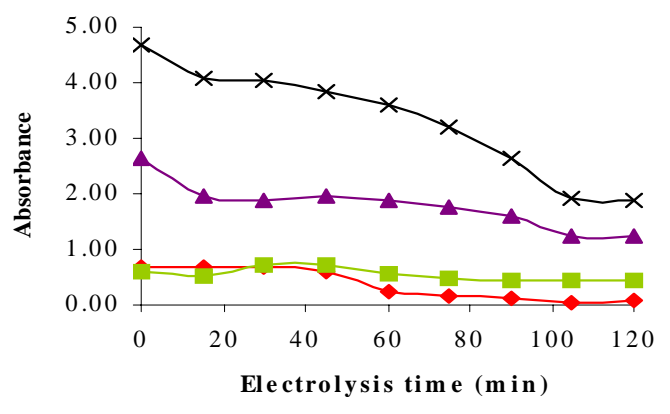

A

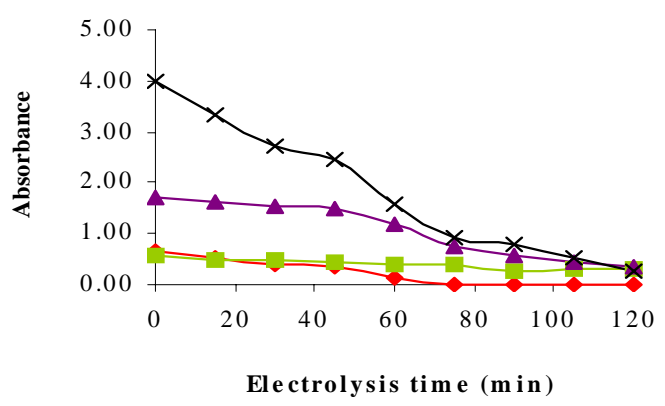

B 
Another important class of plant pigments is the phenolic substances, which include the tannins, the flavonoids, and the various quinone compounds. Most of these materials (except perhaps the tannins) are poorly soluble in water but more soluble in alcohol or other organic solvents. Many of them are valuable natural products, while others (especially the tannins) are regarded as little more than intractable mixtures with unfavourable biological activities and it is generally preferable to remove them along with the pigments.

In a $100 \%$ aqueous medium, it has been shown that tannins can be very efficiently coagulated and removed by electrolysis [22-23]. In this study, we tried to repeat the process in aqueous alcoholic solutions. The hypothesis is that tannins, owing to their polyphenolic nature, should still be easily coagulated by the phenolate salt forming mechanism in addition to the adsorption mechanism [23]. Our experiments showed this to be the case. Thus, for example, at a concentration of $0.1 \%$ tannin in up to $85 \%$ ethanol, a $250-\mathrm{mL}$ solution was almost completely de-tannized within 15 minutes, using aluminium as electrodes and a current of 0.3 A (Figure 8). At a concentration of $1.0 \%$ tannin, the complete detannization time was increased to 80 minutes (Figure 9).

Figure 8. Plot of the residual weight percentage and electrolysis time for $0.1 \% \mathrm{w} / \mathrm{v}$ tannin at $275 \mathrm{~nm} ; \bullet$, 25\% ethanol , $\boldsymbol{\Delta}, 50 \%$ ethanol, $\square, 75 \%$ ethanol and $\diamond$, $85 \%$ ethanolic solution.

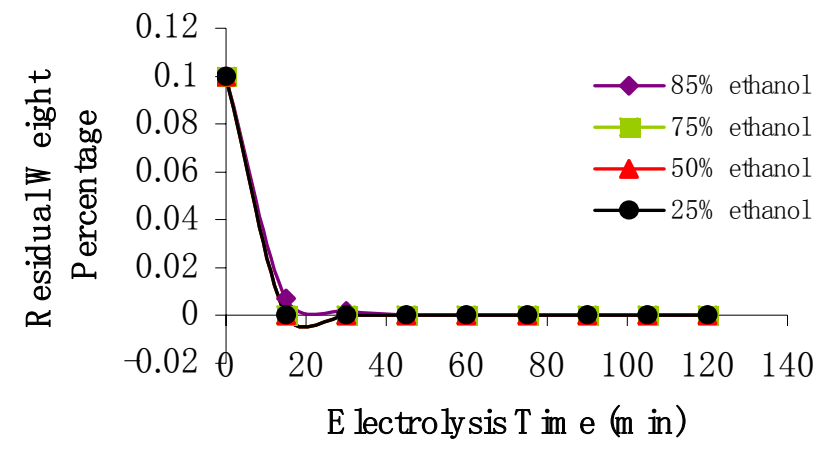

Figure 9. Plot of the residual weight percentage and electrolysis time for $1.0 \% \mathrm{w} / \mathrm{v}$ tannin at $275 \mathrm{~nm} ; \boldsymbol{\Delta}, 25 \%$ ethanol, $\square, 50 \%$ ethanol, $\bullet, 75 \%$ ethanol, and $85 \%$ ethanolic solution.

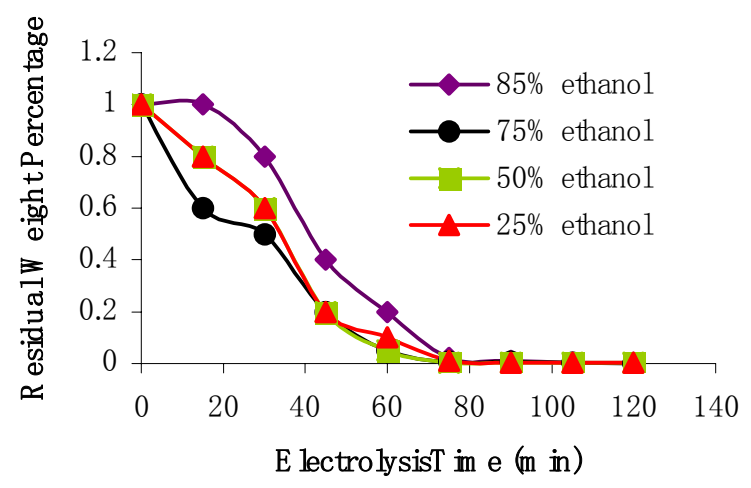


Next, to demonstrate the general trend of the effect of water content in the solvent on the coagulation of phenolic compounds other than tannins, the result of electrocoagulation of a known flavonoid, morin, is presented here as a typical example (Figure 10). It can thus be seen that the effect of the decrease of water content in the solvent on the coagulation of this type of substances is similar to

that of the chlorophylls and the carotenoids, i.e., as the water content in the solvent decreases (or the alcohol content increases), coagulating efficacy also seems to decrease proportionally.

Figure 10. Plot of the residual weight percentage and electrolysis time for $0.1 \% \mathrm{w} / \mathrm{v}$ morin at 415, $420 \mathrm{~nm} ; \boldsymbol{\Delta}, 50 \%$ ethanol, $\square, 75 \%$ ethanol and $\$ 85 \%$ ethanolic solution (a $0.1 \%$ solution of morin in $25 \%$ ethanol cannot be prepared.)

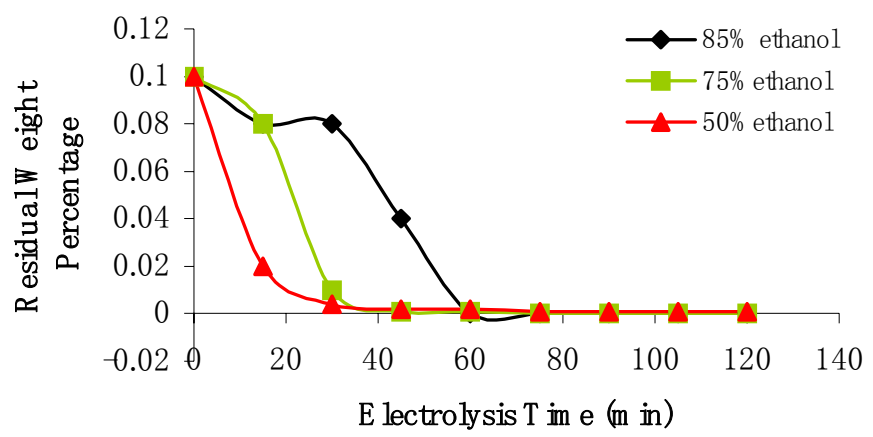

For most natural phenolic compounds, however, probably owing to the active polyhydroxy functions of the substances, coagulation which can occur both by reaction and by adsorption tends to be more complete than that of the chlorophylls and the carotenoids, so that after some time (60 minutes in this case), coagulation is virtually complete, even in solvents with a high percentage of alcohol.

\section{Conclusions}

It has been demonstrated in a systematic manner that in the electrocoagulation in aqueous alcoholic solutions of some important plant pigments, including tannins, the decrease in the percentage of water in the solvent has some negative effects on the degree and efficiency of their coagulation compared with that observed in $100 \%$ aqueous solution. However, the effect is small in the case of tannins and some other phenolic substances. For chlorophylls and carotenoids, this retarding effect is somewhat higher, probably due to only a single mode of coagulation being in operation (viz. adsorption mode). However, even with this unfavourable effect being present, electrocoagulation is still more efficient in removing these organic matrix substances than the conventional method of solvent extraction.

\section{Experimental Section}

\section{General}

All of the tested compounds used were of standard reagent grade, and were used as received. Tannin and $\beta$-carotene were purchased from Fluka Chemica AG (Buchs, Switzerland); morin 
(3,5,7,2',4'-pentahydroxyflavone) was purchased from May \& Baker Ltd (Dagenham, England). Crude chlorophyll was obtained from Spinach oleracea. Air-dried leaves of Solanum laciniatum were obtained from Dr. Jiradej Manosroi, Faculty of Pharmacy, Chiangmai University. Sodium chloride (99.9\%, AR grade) was purchased from Ajax Chemical Co. (Sydney, Australia). Absolute ethanol was purchased from E. Merck (Darmstadt, Germany). Acetone and ethanol (95\%) were of a commercial grade. Aluminium and iron plates were purchased locally. Direct current was sustained by a GW Instek DC power supply. Absorbance was measured on a Genesys 10 spectrophotometer.

\section{Preparation of solutions for electrocoagulation}

A solution of tannin (tannic acid) or morin $(0.01,0.1$, or $1.0 \% \mathrm{w} / \mathrm{v}$ ) was prepared in aqueous ethanol $(25 \%, 50 \%, 75 \%$ or $85 \% \mathrm{v} / \mathrm{v})$. Beta-carotene was dissolved in $27 \%$ ethanol to give a $0.01 \%$ w/v solution. Crude chlorophyll was extracted from Spinach oleracea with 75 or $85 \%$ ethanol at room temperature by grinding $40 \mathrm{~g}$ of the dry plant material with solvent $(200 \mathrm{~mL})$. The filtered solution was used directly in the electrocoagulation experiments. For Solanum laciniatum, the powdered air-dried leaves (20 g) were refluxed for 3 hours with each aqueous alcoholic solution (25\%, 50\%, 75\%, 85\%, $200 \mathrm{~mL}$ ). After filtration, the deep green solutions obtained were used directly in the electrocoagulation experiments.

\section{Electrocoagulation procedures}

\section{1) Morin and tannic acid}

Two aluminum plates (dimensions $15 \times 4 \mathrm{~cm}$ ) were used as electrodes. These were spaced $3 \mathrm{~cm}$ apart and dipped $5.5 \mathrm{~cm}$ deep into a magnetically-stirred aqueous solution (250 $\mathrm{mL})$ of the tested compound ( $0.01,0.1$ or $1.0 \% \mathrm{w} / \mathrm{v}$ solution) in a $400 \mathrm{~mL}$ beaker. Sodium chloride $(0.5 \mathrm{~g})$ was added as an electrolyte. Direct current (0.3 A) from the DC power supplier was then passed through the solution. Every 15 minutes during a 2 hour period of electrolysis, a $4 \mathrm{~mL}$ sample of the solution was withdrawn, centrifuged and taken for an absorbance measurement at an appropriate wavelength (275 $\mathrm{nm}$ for tannin and 415-420 nm for morin). The measured absorbance was then converted into the residual weight percentage of the compound by a calibration curve obtained from a plot of the absorbance versus the concentration for each compound.

\section{2) Chlorophyll, $\beta$-carotene, and Solanum laciniatum}

Aluminium or iron plates $(15.0 \times 3.0 \mathrm{~cm}$. $)$ were washed prior to use with acetone to remove surface grease. A pair of aluminium or iron plates $1.5 \mathrm{~cm}$ apart was immersed $7.0 \mathrm{~cm}$ deep into $200 \mathrm{~mL}$ of each solution in a jacketed 250 -mL beaker for occasional cooling during electrolysis. The solution was agitated throughout the experiment with a magnetic stirrer (250 r.p.m.). Sodium chloride (0.2 g) was added as supporting electrolyte. Direct current (0.9 A, 16.9-31.6 V) was then passed through the solution via the two electrodes. At every 15-minute interval during a 2-hour period of electrolysis, a 4$\mathrm{mL}$ aliquot of the solution was withdrawn and centrifuged for 10 minutes, and the absorbance of the 
supernatant solution was measured at an appropriate wavelength of the absorption maximum for each plant solution (440 and $665 \mathrm{~nm}$ for chlorophyll, $460 \mathrm{~nm}$ for $\beta$-carotene and 408 and $666 \mathrm{~nm}$ for Solanum laciniatum).

\section{Acknowledgements}

Dr. Jiradej Manosroi of the Faculty of Pharmacy, Chiangmai University, is thanked for supplying the leaves of Solanum laciniatum. This research study is supported financially by TRF (Thailand Research Fund) in the form of Medicinal Chemistry Grant and Royal Golden Jubilee PhD Grant for K. J., and by the Commission on Higher Education PhD Grant for N. C. We also thank the Graduate School, Chiangmai University, for partly supporting K.J and N.C. financially.

\section{References and Notes}

1. Vik, E. A.; Carlson, D. A.; Eikum, A. S.; Gjessing, E. T. Electrocoagulation of Potable Water. Water Res. 1984, 18, 1355-1360.

2. Mameri, N.; Yeddou, A. R.; Lounici, H.; Belhocine, D.; Grib, H.; Bariou, B. Defluoridation of Septentrional Sahara Water of North Africa by Electrocoagulation Process Using Bipolar Aluminium Electrodes. Water Res. 1998, 32, 1604-1612.

3. Beck, E. C.; Giannini, A. P.; Ramirez, E. R. Electrocoagulation Clarifies Food Wastewater. Food Technol. Feb. 1974, 28, 18-19.

4. Renk, R. R. Electrocoagulation of Tar Sand and Oil Shale Wastewater. Energy Prog. 1988, 8, 205-208.

5. Dobolyi, E. Experiments Aimed at The removal of Phosphate by Electrochemical Methods. Water Res. 1978, 12, 1113-1116.

6. Groeterud, O.; Smoczynski, L. Phosphorus Removal From Water by Means of Electrolysis. Water Res. 1986, 20, 667-669.

7. Cenkin, V. E.; Belevtsev, A. N. Electrochemical Treatment of Industrial Wastewater. Effluent Water Treat. J. 1985, 25, 243-244.

8. Mrozowski, J.; Zielinski, J. Studies of Zinc and Lead Removal From Industrial Waste by Electrocoagulation. Environ. Protection Eng. 1983, 9, 77-85.

9. Jenke, D. R.; Diebold, F. E. Electroprecipitation Treatment of Acid Mine Wastewater. Water Res. 1984, 18, 855-859.

10. Lee, B. S.; Son, E. J.; Choe, E. K.; Kim, J. W. Electrochemical Treatment of Dyeing Effluent Using Sacrificial Iron Electrodes. J. Korean Fiber Soc. 1999, 36, 329-337.

11. Do J. S.; Chen, M. L. Decolourization of Dye-Containing Solution by Electroagulation. J. Appl. Electrochem. 1994, 24, 785-790.

12. Miwa, K. Extraction and Purification of Plant Components. Jpn. Kokai Tokkyo Koho 78 105,500; [Chem. Abstr. 1979, 90, 3392y].

13. Miwa, K.; Maeda, S.; Murata, Y. Stevia Sweetener Purification by Electrolysis. Jpn. Kokai Tokkyo Koho 79 89,066; [Chem Abstr. 1979, 91, 173681e]. 
14. Miwa, K.; Maeda, S.; Murata, Y. Purification of Stevioside. Jpn. Kokai Tokkyo Koho 79 90,199; [Chem. Abstr. 1979, 91, 206904k].

15. Adduci, J.; Buddhasukh, D.; Ternai, B. Improved Isolation and Purification of Stevioside. J. Sci. Soc. Thailand 1987, 13, 179-183.

16. Phutdhawong, W.; Buddhasukh, D. Simple Isolation and Purification of Glycyrrhizic Acid. J. Sci. Fac. CMU, 1998, 25(2), 87-91.

17. Phutdhawong, W.; Buddhasukh, D. Simple Isolation and Purification of D-Pinitol from Cassia Siamea Lamk by Electrolytic Decolourization. ACGC Chem. Res. Commun., 2000, 10, 61-62.

18. Phutdhawong, W. Ph.D. Thesis, 2002, Chiang Mai University, Thailand.

19. Chowwanapoonpohn, S. Ph.D. Thesis, 2003, Chiang Mai University, Thailand.

20. Jumpatong, K.; Phutdhawong, W.; Chowwanapoonpohn, S.; Garson, M. G.; Pyne, S. G.; Buddhasukh, D. Trends in Electrochemistry Research; Nova Publishers: New York (in press).

21. Jumpatong, K.; Phutdhawong, W.; Buddhasukh, D. Dechlorophyllation by Electrocoagulation. Molecules, 2006, 11, 156-162.

22. Buso, A.; Balbo, L.; Giomo, M. Electrochemical Removal of Tannins from Aqueous Solutions. Ind. Eng. Chem. Res. 2000, 39, 494-499.

23. Phutdhawong, W.; Chowwanapoonpohn, S.; Buddhasukh, D. Electrocoagulation and Subsequent Recovery of Phenolic Compounds. Anal. Sci. 2000, 16, 1083-1084.

Sample Availability: Available from the authors.

(C) 2006 by MDPI (http://www.mdpi.org). Reproduction is permitted for noncommercial purposes. 